\title{
Mobile and E-Commerce: Study of Indian Young Consumer
}

\author{
Prof. Bidyanand Jha*, Dr.K.V.A .Balaji \\ ${ }^{l}$ Assistant Professor, Kirloskar Institute of Advanced Management Studies Prof. and HOD, Department of \\ Mechanical Engineering \\ ${ }^{2}$ Sri Jayachamarajendra College of Engineering, Mysore, Karnataka, India.
}

\begin{abstract}
The mobile gadgets having internet facilities for various operations has gained popularity among young consumers for getting connected with the social and commercial groups. The gap between standardization and adaptation of Mobile Internet for commercial purpose in the country still persists. While industries are looking for transformation of their process from physical to virtual market, empirical research in the field of standardization verses adaptation is still limited in the field of young consumers. In order to enrich the literature in this context, which is currently limited, this paper explores the young Indian consumers' perception of Mobile Internet for commercial purpose. This research is confined to the young consumers residing in metropolitan cities. This research is used to find out the factors that may change the dimension of its use. The study is based on the theoretical background of TAM (Technology Acceptance Model) and the empirical data collected by a standardized questionnaire among young consumers residing in metro city of India. The sample size for the data collection consists of 250 completed and valid responses. The respondents are students, belonging to different undergraduate and post graduate streams, varying in age from 15-22 years. 200 respondents reported that they use Mobile Internet enabled device. The analysis was carried out by using SEM (Structural Equation Modeling). The usefulness, ease to use social networks and trust on the commercial entity found to be influential on both intention to use and the actual usage of Mobile Internet for commercialization among young Indian consumer.
\end{abstract}

Key words: TAM, Standardization, Adaptation, Virtual Market, SEM.

\section{Introduction}

The growing economy of any country results in growing infrastructure that includes Physical, Financial, Human and Social Resources. The growing infrastructure reflects precisely the growth, removal of poverty, structural changes and production processes. Technological Improvement is also a part of structural changes that to be made in society that represents a developing economy. It is also necessary to provide products with technological improvements to refine the process of growth drivers. Mobile as a device and internet as a service has captured bigger market in terms of acceptance and addiction of consumer towards them. Mobile Internet as a part of Infrastructural development has changed the way consumer makes purchase especially in the field of e-commerce. However the usage of Mobile Internet is much slower than expected. Chae and Kim, 2003 defines "Mobile Internet as wireless access to the digitalized contents of the internet via mobile devices."

These devices include mobile phone and laptop computers and all electronic devices which are portable and can be used for internet services anywhere anytime. Using Internet through mobile devices is a fashion and fantasy too. However, its usage is in a growth phase and especially young Indian consumers are very fond of hanging on to the internet for their entertainment and other usage. Hence, it is getting popular among the young Indian consumers to use the mobile devices for the usage of internet. According to various secondary sources $45 \%$ of Korean mobile phone subscribers were also Mobile Internet subscribers, while in Japan, the subscription rate was $81 \%$ (Minges, 2003). For high speed Internet access (Over $2.5 \mathrm{G}$ or $3 \mathrm{G}$ ), as a proportion of Mobile Internet subscribers, the subscription rate is $6.6 \%$ in Japan and 51.1\% in Korea (Minges 2003). On the contrary , the number of users who use their computers (Desktop or Laptop) may not have grown as fast as the industry expected but innovative data plan offered by telecom industry and reduction on price of internet enabled handsets are expected to make up for the gap with an increasing number of users surfing the net on their handsets. According to Google, the number of people hooked with the usage of internet through the mobile phone has almost doubled than the figure of 8-10 million in the year 2009 .

The aim of this study is therefore, to assess consumers' perception of the usefulness and the relevance of Mobile Internet in India through a survey. The TAM model which is widely used for technology adaptation studies is deployed to provide the theoretical foundation for this study. The questionnaire items were developed based on the existing, well established questionnaire used in the TAM literature, with some minor modification to suit this particular case.

The findings demonstrate the applicability of the Technology Acceptance Model in assessing the acceptance of Mobile Internet in India. Consistent with many previous studies, the perceived usefulness and perceived ease of use of Mobile Internet technology were found to have positive impacts on the attitude towards 
using the technology. Attitude in turn strongly influences the behavioral intention to use the Mobile Internet. Finally, the behavioral intention to use Mobile Internet affects the extent of actual usage. In addition to the factors Suggested by the TAM, this study also shows the social influence has a strong positive impact on the attitude towards using Mobile Internet. The understanding of consumers' perception and expectations of Mobile Internet services obtained from this study will be valuable in shaping the future of Mobile Internet in India.

In the next section, the development of the conceptual model of the acceptance of mobile Internet is discussed. The authors then describe the methodology employed in this study, the data validation and analysis process used, and the findings. The authors conclude the paper by acknowledging number limitations of this study and discussing the implications of the findings for Mobile Internet service providers, the research models tested, and for future research.

\section{The Research Model}

Study of factors affecting the adoption of various technological innovations has attracted the attention of researchers and practitioners for many years (Pfeffer, 1982; Chaffe, 1985; King,1990; Keil, 1991; Slappendel, 1996). Various frameworks and models have been developed to explore determinants of technology acceptance and adoption, including the Diffusion of Innovations model (Rogers, 1983), Theory of Reasoned Action (TRA) (Ajzen and Fishbein, 1975), Theory of Planned Behavior (TPB) (Ajzen, 1985), the Technology Acceptance Model (TAM) (Davis, 1989) and various extended models of the TAM (Davis et al., 1989; Dishaw and Strong, 1999; Davis and Venkatesh, 2000). Among the many adoption models, the TAM has been claimed to be the most influential and widely adopted to predict the acceptance and use of various technologies due to its strength in theoretical basis and empirical support (Saga and Zmud, 1994). Therefore, this study has adopted the TAM with minor modifications to assess the acceptance of Mobile Internet in India.

Figure 1 depicts the research model for the acceptance of Mobile Internet used in this study.

The model was mainly derived from the TAM, with three additional constructs, namely 'Visibility' and 'Perceived Cost' (derived from Everett Rogers' Diffusion of Innovations theory), 'Social Influence' (derived from the Theory of Reasoned Action). It must be emphasized that we are measuring perceived cost rather than the amount spent, on the basis that logically, attitudes are most likely to be determined by the level of affordability rather than the market price. These three constructs are shown in italics in Figure 1. Nine relationships between the constructs in Figure 1 are hypothesized, and are discussed below.

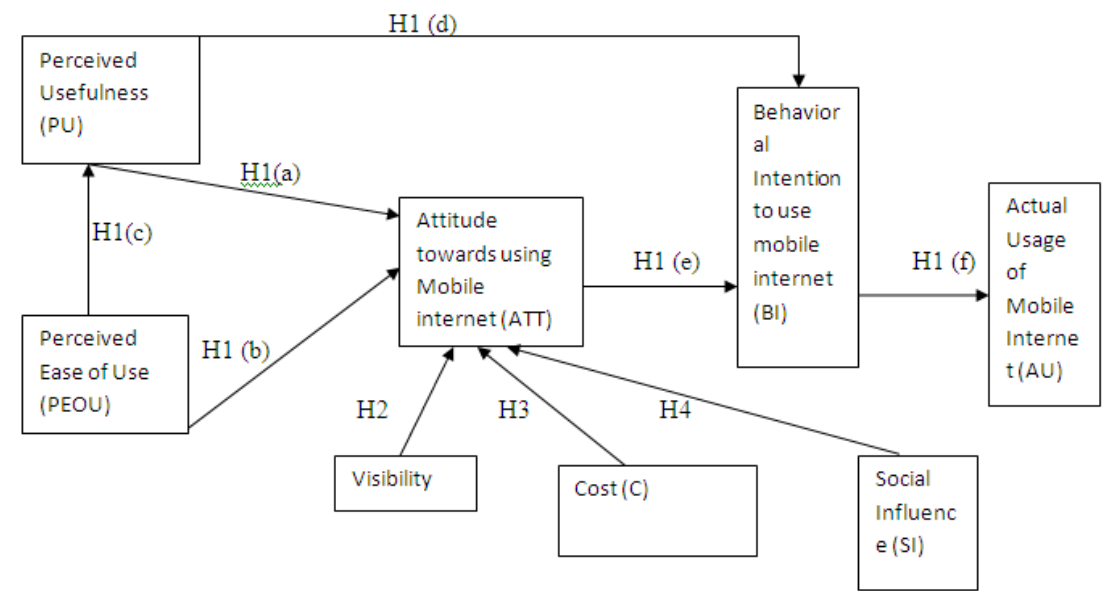

Figure 1 : The Acceptance model of Mobile Internet.

Six hypotheses - H1(a) to H1(f) in Figure 1 - originated from the TAM. The TAM was developed by Davis (1989) based on the Theory of Reasoned Action (TRA) (Ajzen and Fishbein, 1975) to explain computer usage behavior. The goal of the TAM is "to provide an explanation of the determinants of computer acceptance that is general, capable of explaining user behavior across a broad range of end-user computing technologies and user populations, while at the same time being both parsimonious and theoretically justified" (Davis, 1989, p.985). It proposes that 'Perceived Usefulness' (PU) and 'Perceived Ease of Use' (PEOU) largely determine whether or not a technological innovation will be used. PU is defined as "the degree to which a person believes that using a particular system would enhance his or her job performance" while PEOU refers to "the degree to which a person believes that using a particular system would be free of effort" (Davis, 1989, p.320). Based on this, we constructed the following hypotheses in relation to Mobile Internet acceptance: 
H1 (a): There is a positive relationship between Perceived Usefulness and Attitude towards Mobile Internet usage.

H1 (b): There is a positive relationship between Perceived Ease of Use and Attitude towards Mobile Internet usage.

In addition, the improved technology acceptance model (Davis, 1993) proposes that Perceived Usefulness is influenced by Perceived Ease of Use, but not vice versa: Improving the usability of technology should enhance its value, but it must first be useful - no amount of engineering to make a technology easier to use will add value if the technology is not useful to begin with. This relationship has been confirmed in a number of other studies (see for examples, Davis et al., 1989; Davis, 1993; Taylor and Todd, 1995; Chau, 1996). find it useful.

Therefore, we hypothesized that if consumers found Mobile Internet easy to use, then they would also

H1 (c): There is a positive relationship between Perceived Ease of Use and Perceived Usefulness of Mobile Internet.

The TAM further postulates that Behavioral Intention (BI) to use a particular technology is determined by attitude and perceived usefulness. Past studies invariably show that the latter factor has a large impact on intention, either directly, or indirectly via attitude (sometimes via both paths). The size of the total effect (usually shown as $\square \square$ or r2) generally exceeds 0.20 . Thelevel of behavioral intention, in turn, determines the likelihood that actual usage (AU) will occur (Ajzen and Fishbein, 1975; Davis et al., 1989). These relationships were examined in the context of Mobile Internet using the following hypotheses:

H1 (d): There is a positive relationship between Perceived Usefulness and Behavioral Intention to use Mobile Internet.

H1 (e): There is a positive relationship between Attitude towards using and Behavioral Intention to use Mobile Internet.

H1 (f): There is a positive relationship between Behavioral Intention to use and Actual Usage of Mobile Internet.

Besides the constructs proposed by the TAM, three additional constructs are included in our model. First, visibility, which refers to the degree to which an innovation is apparent to the potential adopters (Rogers, 1983), affects attitudes towards adopting the innovation. Second, the perceived cost (affordability) of the innovation, including the initial and ongoing costs affecting the attitude of potential adopters. The following two hypotheses were therefore formulated:

H2: There is a positive relationship between Visibility of the use of Mobile Internet and Attitude towards using it.

H3: There is a negative relationship between the cost of using Mobile Internet and Attitude towards using it.

Finally, according to the Theory of Reasoned Action (Ajzen and Fishbein, 1975), a person's behavioral intention (BI) is also affected by subjective norms (SN). Subjective norm - the social pressure exerted on the person to perform the behavior - is then affected by normative beliefs and motivations to comply (Ajzen, 1985). Thus, a person may choose a particular behavior although he/she is not favorable towards the behavior and its consequences, if he/she thinks that one or more references believe he/she should behave in such a manner and there are sufficient motivations to comply. The effect of subjective norm on behavioral intention is also in accordance with the extended TAM proposed by Davis et al. (1989).

In this study the effect of the subjective norm was assessed in a construct named 'Social Influence (SI)' (Figure 1). It has been reasoned that if supervisors/seniors, co-workers, or relatives believe that Mobile Internet is useful, and then a person might agree and accept their belief and in turn establish an intention to use it. However, because Mobile Internet is still in the early stages of adoption in India, it has been hypothesized that social influence would positively influence the attitude (instead of the intention to use), which would then affect the intention to use. This would allow one to observe whether the existence of social influence would affect a person's decision to use Mobile Internet or not.

H4: There is a positive relationship between Social Influence and the Attitude towards using Mobile Internet.

In summary, the model shown in Figure 1 hypothesizes that perceptions of usefulness, ease of use, and cost as well as the visibility of a technology and the influence of one's social network (social influence) all 
jointly determine attitudes towards that technology. Attitude influences intention to use, which itself determines whether or not the technology is used.

\section{Research Design}

To test these hypotheses, a research instrument specifically designed for determining the consumers' perceptions of Mobile Internet in India was administered. An online questionnaire was developed to collect the required data in a most efficient manner possible (Batinic, 1997). This questionnaire was then distributed via electronic mail to potential participants. The population of interest was any existing or potential user of Mobile Internet in India. Participants were identified via University internal mailing lists, as well as a list of professionals in industry. To reach as many potential participants as possible, a type of "snowball" sampling technique was also employed, in that each message included additional clause "please forward this email to any one you think might be interested in this study" in the invitation email.

To recruit people, an initial invitation letter describing the project and seeking participation was emailed to all potential participants. Potential participants expressed their agreement to participate by replying to the invitation e-mail. An e-mail detailing the URL of the questionnaire was then sent out to each person. A department store voucher - given to a randomly chosen participant at the end of the survey - was offered as an incentive to encourage participation.

To enhance the validity and reliability of the questionnaire, each statement was phrased in the simplest possible way, and negative (reverse-coded) statements were not used. Pilot testing was conducted with five individuals: three academics, one researcher and one IT consultant. Following the pilot test, the definition of Mobile Internet was refined, ambiguous statements were identified and improved, and potentially important measures that had been overlooked were included in the final questionnaire.

The questionnaire items for this study were developed based on various sources (see for example, Davis, 1989; Rhee and Riggins, 1997; Hu et al., 1999; Malhotra and Galletta, 1999; Tan and Teo, 2000; Wu and Lin, 2000), since it is practical to use existing, well-developed questionnaires that have been tested for their validity and reliability (Lucas, 1991). Table 1 summarizes the questionnaire items for each construct of this study. Some information on the costs of using Mobile Internet services in India was provided to the participants. For each item, the survey respondents were requested to indicate whether they agree or disagree based on a fivepoint Likert scale: from 'strongly disagree' to 'strongly agree'.

\begin{tabular}{|c|c|}
\hline \multicolumn{2}{|c|}{ Perceived Usefulness } \\
\hline 1. & Using mobile Internet can improve my efficiency in my daily work. \\
\hline 2. & Using mobile Internet can save me a lot of time in general \\
\hline 3. & Using mobile Internet can enhance my effectiveness in carrying out my daily work. \\
\hline 4. & Using mobile Internet enables me to do my work conveniently. \\
\hline 5. & Using mobile Internet can increase my productivity. \\
\hline \multicolumn{2}{|c|}{ Perceived Ease of Use. } \\
\hline 1. & Mobile Internet is/might be easy to use. \\
\hline 2. & It is/might be easy to become skillful at using mobile Internet. \\
\hline 3. & Mobile Internet is /might be user friendly \\
\hline \multicolumn{2}{|c|}{ Attitude towards using mobile internet } \\
\hline 4. & Using mobile Internet is/might be a good idea. \\
\hline 5. & Using mobile Internet is/might be a pleasant experience. \\
\hline 6. & Using mobile Internet is/might be beneficial to me. \\
\hline \multicolumn{2}{|c|}{ Behavioral Intention of use mobile internet } \\
\hline 7. & I intend to use mobile Internet when the service becomes widely available. \\
\hline 8. & Whenever possible, I intend to use mobile Internet. \\
\hline 9. & I intend to use mobile Internet if it is inexpensive. \\
\hline 10. & I intend to use mobile Internet regardless of the price. \\
\hline \multicolumn{2}{|c|}{ Visibility } \\
\hline 11. & I have seen others (from various media) using mobile Internet. \\
\hline 12. & In my organization / university, I often see mobile Internet being used. \\
\hline 13. & I have seen mobile Internet being used outside my organization / university \\
\hline 14. & I often see others using mobile Internet in public. \\
\hline \multicolumn{2}{|c|}{ Social Influence } \\
\hline 15. & I will use mobile Internet if the service is widely used by people in my community \\
\hline 16. & I will adopt mobile Internet if my supervisors / seniors use it. \\
\hline 17. & I will adopt mobile Internet if my friends use it. \\
\hline 18. & I will adopt mobile Internet if my family members / relatives use it. \\
\hline \multicolumn{2}{|r|}{ 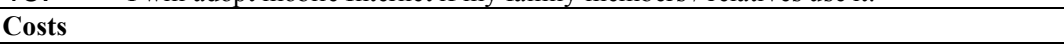 } \\
\hline 19. & The costs of using Mobile Internet are reasonable \\
\hline
\end{tabular}




\begin{tabular}{|ll|}
\hline 20. & Mobile Internet offers value for money. \\
\hline Frequency \\
\hline $21 . \quad$ The number of times you used mobile internet for E-Commerce. \\
a) & Zero \\
b) & One \\
c) & Two \\
d) & Three \\
e) & More than three \\
\hline
\end{tabular}

Table 1. The Questionnaire Items

\section{Data Analysis}

The hypothesized research model depicted in Figure 1 was analyzed using AMOS 5.0, a powerful structural equation modeling (SEM) tool. Applying standard SEM techniques, the analysis was conducted in two phases. In phase-1, the adequacy of the measurement model was assessed, while in phase-2, the structural model was assessed. In assessing the measurement model, the aim was to ensure that for each construct, the measures used are all captured a similar concept, that these concepts were distinct from each other, and that the specification of both the individual constructs and the overall model was parsimonious. This phase therefore involved estimating reliability coefficients - to determine the composite reliability of each latent construct as well as the convergent and discriminant validity of the research instrument as a whole. In assessing composite reliability, Fornell (1982) recommends retaining items that load highly on their respective measures. In particular, item loadings of approximately 0.70 are regarded as desirable because at this level, each item explains nearly half of the variance in the unobserved, or latent, construct. As a result of this procedure, three measures were dropped (Social2, i.e. item 2 in social influence, Visible1, and Intend2) on the basis that their loadings indicated a very poor match with the relevant construct. Table 2 summarizes the reliability of each latent construct in the research model.

Construct Alpha Score.

\begin{tabular}{|l|l|}
\hline Attitude towards use & 0.86 \\
\hline Cost & 0.85 \\
\hline Intention to Use & 0.82 \\
\hline Perceived ease of use & 0.82 \\
\hline Perceived usefulness & 0.88 \\
\hline Social influence & 0.88 \\
\hline Visibility & 0.83 \\
\hline
\end{tabular}

Table 2: Latent Construct Reliability

Discriminant validity - the extent to which sets of measures capture distinct constructs - was determined by comparing each measure's correlation with every other measure. Following Fornell et al. (1982), the components of a construct were deemed to have adequate discriminant validity if they correlated more highly with each other than with measures of other constructs. Using this procedure, two measures were further eliminated that exhibited high correlations with components of other constructs (Usefulness item 3 and Intention item 4). Two measures, efficiency (Usefulness item 2) and the binary variable "I have used Mobile Internet technology", were eliminated because of multi-co linearity problems. The problem with efficiency appears to be that a substantial number of respondents equated it with effectiveness. Frequency of use is the only indicator variable for usage due to high levels of correlation between it and all other measures of usage collected: have ever used (yes/no), use mobile phone (yes/no), and use other mobile device (yes/no). The high level of correlation produced unstable results in the SEM estimation procedure, and so given the choice between a categorical variable and a number of binary variables, it was decided to use the variable that provided the most reliable information (frequency of use). However, it must be noted that frequency is also not an ideal measure: it is coded on a scale from 0 to 11, with the values indicating: never used (0), used once (1), used 2-5 times (2), used 6-10 times (6), and used regularly (11).

\section{Measure Index value}

\begin{tabular}{|l|l|}
\hline CFI & 0.92 \\
\hline NFI & 0.85 \\
\hline PCFI & 0.78 \\
\hline PNFI & 0.72 \\
\hline RMSEA & 0.07 \\
\hline
\end{tabular}

Table 3: Fit Indices 
Finally, the adequacy of the structural model was assessed using the goodness of fit measures shown in Table 3. The number of criteria by which model fit can be measured means that multiple measures are required to give an indication of the degree of fit. Unfortunately, there is little consensus on which measures should actually be used (Maruyana, 1998; Byrne, 2001). Following Byrne's recommendations, the Comparative Fit Index (CFI) is reported, the Normed Fit Index (NFI), the Parsimony-Adjusted CFI and NFI (PCFI and PNFI), and the Root Mean-Squared Error of Approximation (RMSEA). CFI and NFI values higher than 0.90 indicate a potentially good fit between the data and the research model; however there is some evidence that the NFI underestimates fit for small samples, so the CFI is generally regarded as the index of choice (Byrne, 2001). The PCFI and PNFI measures, which take into account the complexity of the model, are less subject to this influence. The values reported for our model, of 0.78 and 0.72 , are indicative of a good fit (Byrne, 1994). Finally, the RMSEA is considered to indicate a good fit if the value is below 0.1 and an excellent fit if 0.05 or lower (Hu and Bentler, 1999). Therefore, it is concluded that our model is an adequate representation of the data.

Finally, Pointed-Biserial Correlation, used when measuring on a continuous variable and a dichotomous variable, was appropriate to test the hypothesis H1 (f). A 5\% level of significance was used to examine the association between variables as this is considered an acceptable standard for social science research (Neuman, 1994).

\section{The Survey Findings}

The final sample consisted of 250 completed and valid responses. The age of the respondents varied from 15 to 22 years. The classification reported were undergraduate student (150), postgraduate student (100). Out of 250, 200 respondents reported that they had Mobile Internet enabled device, primarily the mobile phone.

The results of the structural equation modeling analysis are shown in Figure 2 (factor scores and direct effects) and Table 4 (total effects). The diagram shows path coefficients in the form of standardized regression coefficients, as well as the statistical significance of each coefficient.

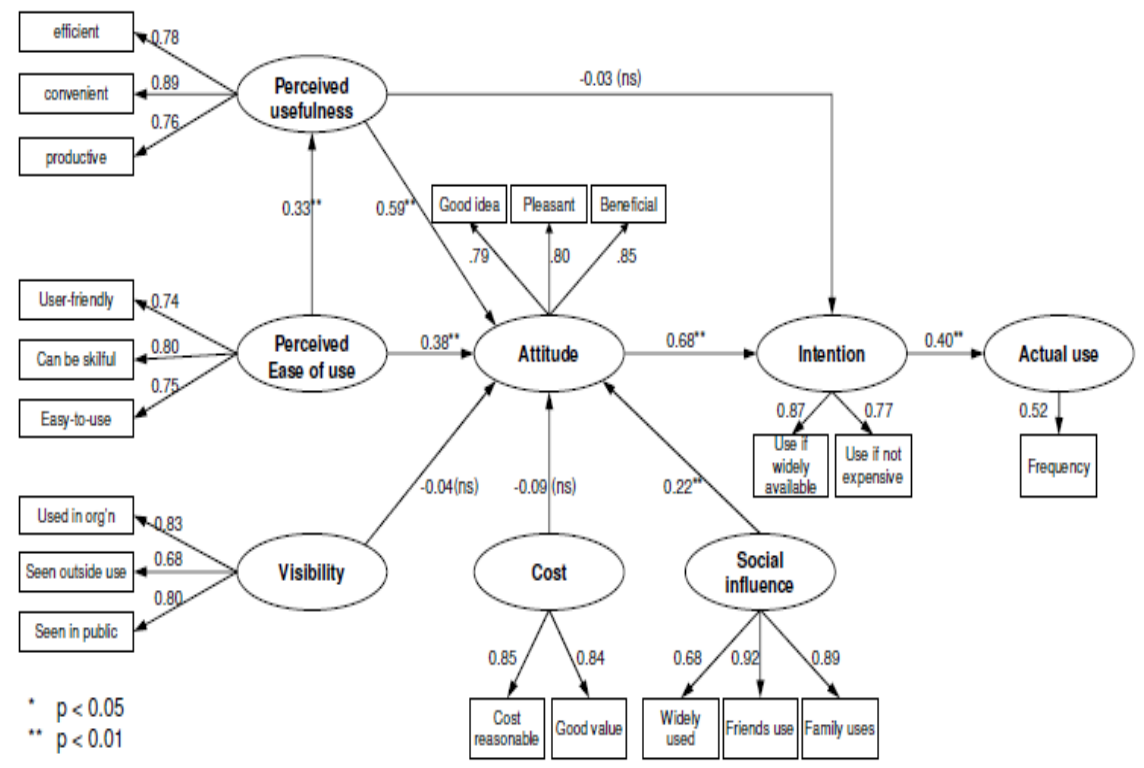

Fig2: SEM Path Coefficient.

Consistent with hypothesis 1c, perceived ease-of-use has a strong influence on perceived usefulness. The model also supports hypotheses $1 \mathrm{a}, 1 \mathrm{~b}$, and 4 in that perceived usefulness, perceived ease of use, and social influence all have a significant influence on attitude. However, no support was found for the hypothesized relationships between perceived usefulness and intention (H1d), visibility and attitude (H2), and cost and attitude (H3). Given the strong relationship between usefulness and attitude, the lack of support for H1d is at first surprising. However, although the direct effect is not statistically significant, as shown in Table 4, usefulness actually has a substantial indirect effect via attitude ( $\square \square=0.36$ ).The relationship between intention and actual usage was also examined. Given the imprecision of the measure of usage, the presence of any relationship is encouraging. That the effect size is not large ( $\square \square=0.40, \mathrm{p}<0.01$ ) is therefore not surprising, and almost certainly understates the actual relationship between intention and frequency of use. 


\begin{tabular}{|l|l|l|l|}
\hline Independent Variables & \multicolumn{2}{|l|}{ Effect on Dependent } & Actual Use \\
& Attitude & Intention & .40 \\
\hline Intention & - & - & .27 \\
\hline Attitude & & .68 & .15 \\
\hline Perceived Usefulness & .59 & .36 & .15 \\
\hline Perceived ease of use & .57 & .38 & .06 \\
\hline Social Influence & .22 & .15 & - \\
\hline Visibility & - & - & - \\
\hline Cost & - & - & \\
\hline
\end{tabular}

Table 4: Standardized total effects

To sum up, tests of the structural model indicate that perceived ease of use and usefulness are the dominant factors affecting attitude, and that all three have a substantial influence on both intention to use and frequency of use. Social networks, particularly the behavior of friends and family members, have a small but significant effect on attitude formation. In contrast, visibility and perceived cost appear to play no role in either attitude formation or usage intentions.

That visibility has no effect is, in hindsight, not surprising, given that it is essentially an invisible service: one cannot easily observe the use of a specific type of communications services. Instead, knowledge of usage is most likely to come from close associates. The authors speculate the lack of impact of cost on attitude, particularly given that some participants specifically cited high Mobile Internet connection and data communication costs as a problem, is due to the fact that perceived cost is a function of the type of communications contract used by each participant. Although cost was clearly an issue for some, if Mobile Internet capability is bundled into a mobile phone contract, Internet cost is probably not separable from other communications costs, and so has no influence on attitudes.

Finally, Pointed-Biserial Correlation was employed to test the hypothesis H1 (f). To measure the actual usage of Mobile Shopping in India, the survey respondents were asked the number of times they had used Mobile Shopping, based on the following scale: never, 1, 2, 3 or more. The responses were then recomputed into a two-point scale: $0=$ never used and $1=$ used. Pointed-Biserial Correlation was then performed with one dichotomous variable (AU) and one continuous variable (BI). The Pointed-Biserial Correlation was then calculated using a Pearson's correlation, as shown in Table 5.

Table 5: Point-Biserial Correlation between Actual Use and Behavioral Intention to Use Mobile Commerce.

\begin{tabular}{|l|l|l|l|}
\hline & & Actual Usage (AU) & Behavioral Intention (BI) \\
\hline Actual Usage (AU) & Pearson Correlation & 1.000 & $.249^{*}$ \\
& Sig. (2-tailed) & .331 & .000 \\
& $\mathrm{~N}$ & & 323 \\
Behavioral Intention (BI) & $\begin{array}{l}\text { Pearson Correlation } \\
\text { Sig. (2-tailed) }\end{array}$ & $.249^{*}$ & \\
& $\mathrm{~N}$ & 323 & 1.000 \\
& & .000 & 324 \\
\hline
\end{tabular}

* Correlation is significant at the 0.01 level (2-tailed).

The result demonstrates that there is a weak positive relationship between $\mathrm{BI}$ and $\mathrm{AU}(\mathrm{r}=0.249$; $\mathrm{p}=0.000)$ at 0.01 significance level. Thus, there exists a positive relationship between Behavioral Intention to use MOBILE COMMERCE with the Actual Usage of MOBILE COMMERCE in India. This suggests that the hypothesis H1 (f) should be accepted.

\section{Discussion and Conclusion}

The findings of the study have demonstrated the applicability of the Technology Acceptance Model in assessing the acceptance of Mobile Internet in India. All of the constructs proposed in the TAM and their relationships, except for the relationship between the perceived usefulness and intention to use mobile technology, were found to be relevant in this study. The perceived usefulness of Mobile Internet is influenced directly by the perceived ease of use. In addition, these two constructs do positively affect the attitude towards using Mobile Internet and this attitude, in turn, influences the intention and the actual use. The study further shows that the perceived usefulness and the intention to use mobile technology have an indirect relationship via the attitude towards Mobile Internet. Furthermore, this study has showed that social influence plays an important role in shaping the attitude of adopters and potential adopters of Mobile Internet, as demonstrated in this study. However, costs and visibility of the technology were found not to have an impact on the attitude. Figure 2 presents the revised model of the acceptance of Mobile Internet in India. 
Overall, the results indicate that there is a positive attitude towards using Mobile Internet/ facilities (average response of 3.48 for the three items in this construct). However, a careful look at the results of the study indicates that Mobile Internet technology still has some way to go in terms of its functionality. Specifically, the majority of the participants perceived this technology as not very useful with the average responses of 2.94 (based on a five-point scale:1 (strongly disagree) to 5 (strongly agree)), although it was perceived to be reasonably easy to use (average of 3.29). In particular, the participants appear to be unsatisfied with the costs of using Mobile Internet services as indicated by the average response of 2.16. A closer look at the survey results shows that a high proportion of the participants have an intention to use Mobile Internet if it is inexpensive (average response of 3.99).

All these observations suggest that there is large potential for Mobile Internet to flourish in India. However, for this to happen, the telecommunication providers must enhance the ease of use and usefulness of Mobile Internet services for the users given that these two factors play a critical role in the formation of a positive attitude towards the use of the technology. The strong effect of usefulness confirms the need to develop content and applications which people will find useful, although results also indicate that substantial effort needs to be made to ensure that content and applications are as easy to use as possible. Finally, although the survey found that costs do not appear to play a significant role in the attitude formation process, the strong impact of social networks suggests that a variety of strategies including cost reduction should be used to attract costsensitive opinion leaders who, in turn, will influence the intentions of potential adopters to use Mobile Internet.

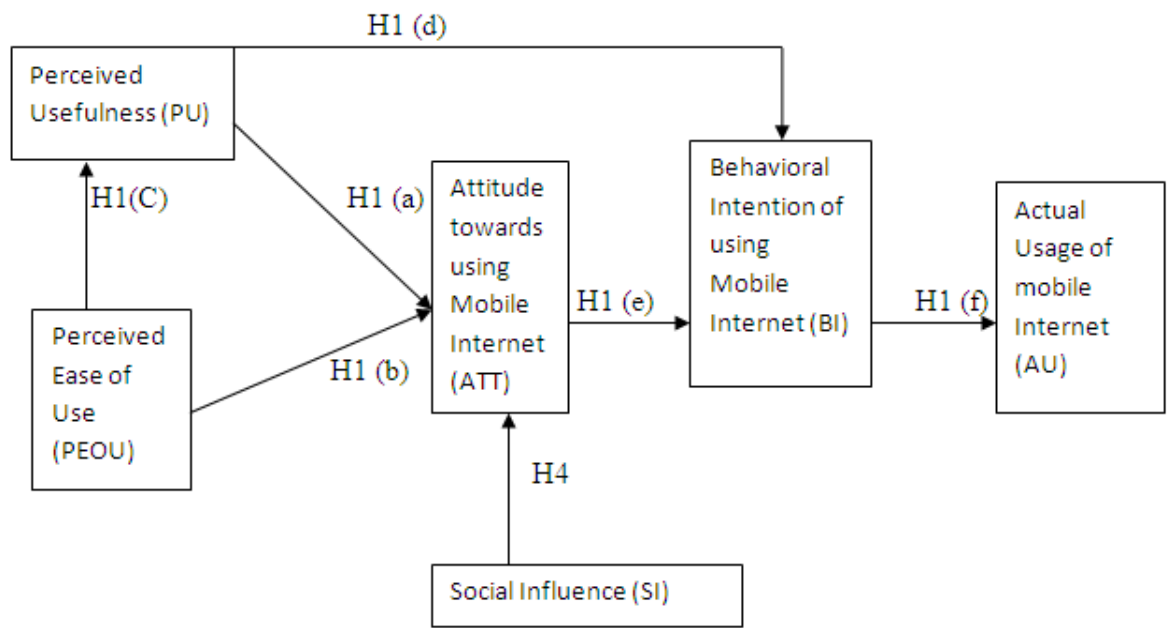

Fig 3 : Revised Model of Mobile Internet Acceptance.

One of the limitations of this study is that since the survey respondents were dominated by Victorian respondents and the majority are students, the results of this study may not generalize beyond the sample. However, it is expected that Victorian consumers should not differ significantly from other Indian consumers in general, particularly in terms of their familiarity of the capabilities of Mobile Internet technology and their access to the mobile devices with the Internet capability. Furthermore, given that data from the 2001 Indian Census indicates mobile phone users are predominantly young and male (3), we believe that the demographic used in our study is highly representative of Mobile Internet users in general.

To complement the findings of this study, future research could be performed to further explore the reasons for the slow uptake of Mobile Internet in India by assessing customer behavior and market environment. It would also be useful to compare results with other countries in which Mobile Internet is used widely in order to further identify some factors that can promote the growth of Mobile Internet in India.

\section{Future Scope for the research:}

With the understanding of the above implication, the authors would like to offer the following suggestions for the further research in mobile commerce.

1. The development in RFID technology seems to offer new avenues for growth and opportunities in this emerging frontier. This technology is in the market for many years but it has recently gained importance as technology used in supply chains. Hence, it gives an opportunity for further investigation, specially the impact on supply chains.

2. The above findings do not explore the utility of Mobile Internet in B2B Consumer Market. Hence, there exist an opportunity to test the model in B2B Business Environment. 
3. The future research can explore the slow uptake of Mobile Internet in India by assessing customer behavior and market environment.

4. The future research can also explore the Cross-cultural variance of consumers taste \& preference and adaptation of m-commerce.

5. The future research can explore the trust factor of consumer on the payment gateway of e-commerce portals and the impact on Actual usage.

\section{References}

[1]. Ajzen, I. (1985), "The Theory of Planned Behavior", Organizational Behavior and Human Decision Processes, 50, $179-211$.

[2]. Ajzen, I. and Fishbein, M. (1975), Understanding Attitudes and Predicting Social Behavior, NJ Prentice Hall.

[3]. Batinic, B. (1997), How to Make an Internet Based Survey?,

[4]. http://194.77.76.10/index.htm/teste/how to.htm, last accessed May 2001.

[5]. Byrne, B. M., (1994), "Testing for the factorial validity, replication, and invariance of a measuring instrument: A paradigmatic application based on the Maslach Burnout Inventory," Multivariate Behavioral Research, 29(3), 289-311.

[6]. Byrne, B. M., (2001), Structural Equation Modeling with AMOS: Basic Concepts, Applications, and Programming. Lawrence Erlbaum Associates, Mahwah, NJ.

[7]. Chae, M. and Kim, J. (2003), What's so different about the Mobile Internet? Communications of the ACM, 46(12): 240-247.

[8]. Chaffe, E.E. (1985), "Three Models of Strategy", Academy of Management Review, 10, 89-98.

[9]. Chau, Y.K. (1996), "An Empirical Assessment of a Modified Technology Model", Journal of

[10]. Management Information Systems, 13 (2).

[11]. Churchill, G.A.J. (1979), "A Paradigm for Developing Better Measures of Marketing Constructs", Journal of Marketing Research, 15, 64-73.

[12]. Davis, F.D. (1989), "Perceived Usefulness, Perceived Ease of Use and User Acceptance of Information Technology", Management Information Systems.

[13]. Davis, F.D. (1993), "User Acceptance of Information Technology: System Characteristics, User

[14]. Perceptions and Behavioral Impacts", International Journal of Man-Machine Studies, 38 (3).

[15]. Davis, F.D., Bagozzi, R.P. and et al. (1989), "User Acceptance of Computer Technology: A Comparison of Two Theoretical Models", Management Science, 35 (8).

[16]. Davis, F.D. and Venkatesh, V. (2000), "A Theoretical Extension of the Technology Acceptance

[17]. Model: Four Longitudinal Field Studies", Management Science, 46 (2), 186-204.

[18]. Dishaw, M.T. and Strong, D.M. (1999), Extending the Technology Acceptance Model with Task-

[19]. Technology Fit Constructs, Elsevier Science.

[20]. Fink, A. (1995), The Survey Handbook, Sage Publication, Inc.

[21]. Fornell, C. R. (1982), "A Second Generation of Multivariate Analysis", Volume I and II: Methods, New York.

[22]. Fornell, C. R., Tellis, G. J. and Zinkhan, G. M. (1982), "Validity Assessment: A Structural Equations Approach Using Partial Least Squares," In An Assessment of Marketing Thought and Practice (Eds, B. J. Walker, et and al.) American Marketing Association, Chicago.

[23]. Gefen, D. and Straub, D. (2000), "The Relative Importance of Perceived Ease of Use in Is Adoption: A Study of E-Commerce Adoption", Journal of Association for Information Systems, 1 (8).

[24]. Hu, P.J., Liu, O., and et al. (1999) Examining the Technology Acceptance Model Using Physician Acceptance of Telemedicine Technology, Journal of Management Information Systems, 16 (2), 91-112.

[25]. Hu, L. and Bentler, P. M. (1999), "Cutoff Criteria for fit Indexes in Covariance Structural Analysis: Conventional Criteria Versus New Alternatives," Structural Equation Modeling: A Multidisciplinary Journal, 6(1), 1-55.

[26]. Keil, M. (1991), Managing MIS Implementation: Identifying and Removing Barriers to Use, Harvard University.

[27]. King, N. (1990), Innovation at Work: The Research Literature, Innovation and Creativity at Work, M.A. West and J.L. Farr, Chichester: Wiley, 15-80.

[28]. Lucas, H.C. (1991), Methodological Issues in Information Systems Survey Research, The Information Systems Research Challenge: Survey Research Methods, K.L. Kraemer, Boston, Harvard Business School, 273-285.

[29]. Malhotra, Y. and Galletta, D.F. (1999), "Extending the Technology Acceptance Model to Account for Social Influence: Theoretical Bases and Empirical Validation", The 32nd Hawaii International Conference on Systems Sciences, Hawaii, 1-14.

[30]. Maruyana, G. M., (1998), "Basics of Structural Equation Modeling". Sage Publications, Beverly Hills, CA.

[31]. Minges, M. (2003), "Is the Internet mobile? Measurements from Asia-Pacific", Presented at The

[32]. International Telecommunications Society Asia-Australasian Regional Conference, M-business, E-commerce and the Impact of Broadband on Regional Development and Business Prospects. Perth. 22-24 June.

[33]. Neuman, W.L. (1994), Social Research Methods: Qualitative and Quantitative Approaches, Massachusetts, Allyn and Bacon.

[34]. Nunnaly, J.O. (1978), Psychometric Theory, New York, McGraw-Hill.

[35]. Ostlund, L.E. (1974), Perceived Innovation Attributes as Predictors of Innovativeness, Journal of Consumer Research, 1, $23-29$.

[36]. Pallant, J. (2001), SPSS Survival Manual: A Step by Step Guide to Data Analysis Using SPSS, Crows Nest, Allen and Unwin.

[37]. Pfeffer, J. (1982), Organizations and Organization Theory, Boston, Pitman.

[38]. Rappoport, P., Taylor, L. D., \& Kridel, D. J. (2003), Willingness-to-Pay and the Demand for Broadband Service. In A. L. Shampine (Ed.), Down to the Wire: Studies in the Diffusion and

[39]. Regulation of Telecommunications Technologies (pp. 75-86). New York: Nova Science Publishers, Inc.

[40]. Rhee, H.S. and Riggins, F. (1997), Gvu's WWW User Surveys: High Level Summary of Internet Banking Survey,, http://www,gvu.gatech.edu/user_survey/survey-1997-04/graphs/banking/report.html, last accessed May 2001.

[41]. Rogers, E.M. (1983), Diffusion of Innovations, New York, The Free Press.

[42]. Saga, V.L. and Zmud, R.W. (1994), "The Nature and Determinants of It Acceptance, Routinization and Infusion", IFIP Transaction: Computer Science and Technology, 45, 67-86.

[43]. Slappendel, C. (1996), "Perspectives on Innovation in Organizations", Organization Studies, 17 (1), $107-129$.

[44]. Tan, M. and Teo, T., S.H. (2000), "Factors Influencing the Adoption of Internet Banking", Journal of Association for Information Systems, 1 (5)

[45]. Taylor, S. and Todd, P.A. (1995), "Understanding Information Technology Usage: A Test Competing Models", Information Systems Research. 
[46]. Urbaczewski, A., Valacich, J. and Jessup, L. (2003), "Mobile commerce: Opportunities and Challenges". Communications of the ACM, 46(12): 31-32.

[47]. Webster, F.E.J. (1969), "New Product Adoption in Industrial Markets: A Framework for Analysis", Journal of Marketing Research, $33(3), 35-39$.

[48]. Wu, S. and Lin, C.S. (2000), "Exploring Users Intention and Behavior of the Portal Site: Application of Technology Acceptance Model", The 4th Pacific Asia Conferences in Information Systems, Hong Kong, China, CD ROM. 